\title{
Derechos de propiedad en la Constitución de los Estados Unidos de Colombia de 1863
}

\author{
Property rights in the Constitution of the United States of Colombia of \\ 1863
}

\section{Fernando Salazar Silva'y Alba Liliana Cuaspud Cáliz ${ }^{2}$}

\section{Revista \\ Educación y Sociedad}

Citar como: Salazar, F. y Cuaspud, A. L. (2021). Derechos de propiedad en la Constitución de los Estados Unidos de Colombia de 1863. Revista Educación y Sociedad, 02(03), 35-47. doi: $10.53940 /$ reys.v2i3.64

Artículo recibido: 02-10-2021 Artículo aprobado: 10-01-2021 Arbitrado por pares

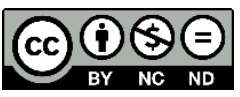

\section{ACEES}

\section{Resumen}

El trabajo que el lector tiene en sus manos pretende hacer una aproximación a las dificultades para la consolidación de los Derechos de Propiedad en el contexto de la Constitución de los Estados Unidos de Colombia de 1863. El tratamiento de este tema pasa por entender el papel que jugó la concepción de derecho que llegó a América Latina y sus implicancias sobre la propiedad privada. Ahora bien, aproximarnos a este problema es preciso enunciar que la libertad individual, en el sentido jurídico-económico, es la base de los derechos de propiedad.

\section{Palabras clave: propiedad, derechos de propiedad, institución, seguridad jurídica}

\section{Abstract}

The work that the reader has in his hands tries to make an approximation to the difficulties for the consolidation of Property Rights in the context of the Constitution of the United States of Colombia of 1863. The treatment of this subject goes through understanding the role that He played the concept of law that reached Latin America and its implications on private property. Now, to approach this problem, it is necessary to state that individual freedom, in the legal-economic sense, is the basis of property rights.

Key words: property, property rights, institution, legal security 


\section{Introducción}

La concepción de propiedad llegada a América fue la del derecho romano, aquella que vincula a la cosa con las personas (derecho real). Los españoles crearon para la región, lo que se conoció como el derecho indiano, el cual es una derivación del derecho castellano, pero sin las limitantes al interés público. Siendo ello así, se aprecia dos implicancias de este derecho indiano sobre la manera de pensar los derechos de propiedad: primero, la propiedad es un atributo de la cosa; y segundo, que es un derecho positivo, es decir, un hecho deliberado orientado a principios materiales. Nótese que esta idea es muy particular, pues intenta mostrar que la raíz del derecho indiano permanece en la manera de pensar y actuar del hombre latinoamericano y esto lo lleva a concebir la libertad individual como algo subsidiario.

De acuerdo con Salazar (2011) las circunstancias históricas de la región han constreñido la idea de la propiedad como incentivo para la generación de riqueza. Si bien es cierto de la importancia que tiene la seguridad jurídica, la construcción de una escala valorativa sobre la propiedad ha tenido sus obstáculos lo que dificultado comprender la propiedad como un proceso competitivo.

El que los otros reconozcan que cualquier cosa, que le sirva a otro tanto o más que a mí, me pertenece con exclusión de todos los demás por el sólo hecho de tenerlo en mi poder, es definitivamente una caracterización de la civilización. La propiedad, al igual que las sociedades humanas, puede explicarse a partir de su evolución desde formas simples, como la ocupación en la época de la caza, el pastoreo, incluso la agricultura, hasta formas más complejas como la propiedad individual y transmisible a los hijos (Smith, 1996).

Así, mismo los adelantos alrededor de la regulación y ordenación de tal propiedad, han respondido a las necesidades de cada momento, pero dándose también que, como en todo proceso y acción humana, los adelantos y las concepciones anteriores, en materia de derechos de propiedad, se yuxtaponen, sobreponen y perviven.

Según el profesor Ghersi (2008) la propiedad contemporánea, que nos viene del siglo XVII, es el resultado de un proceso evolutivo que corresponde al desarrollo de los mercados. Se caracteriza por ser un derecho, en primer lugar, nominalista, donde el individuo es el sujeto de derecho; y, en segundo lugar, personalista, es decir que vincula a las personas con las personas.

Sin embargo, la cadena argumental no siempre fue así. El derecho romano se encargaba de declarar el orden natural de las cosas. Naturalmente, en un escenario de equilibrio, el derecho tiene la función de reestablecer el orden en caso de algún desajuste. Parece advertir que estamos fundamentalmente ante un concepto descriptivo. De ahí resulta que son los objetos susceptibles de derechos y no los individuos. Esta idea de negar al individuo, dio lugar hacia el siglo XVI con Guillermo de Ockham, lo que se denominó el nominalismo. El investir al individuo de derechos muestra la aceptación del libre mercado.

Una vez establecido el derecho en el subjetivismo, se abren dos posibilidades de existencia. En la primera mitad del siglo XVII, de acuerdo al profesor Ghersi (2008), Hugo Grocio lo divide metodológicamente en derechos reales y derechos personales. Es un hecho que los primeros, relacionan a las personas con las cosas; y los segundos, asocian a las personas con las personas.

Lo anterior si bien pone de manifiesto el debate en torno a los derechos de propiedad, es claro que en la medida que los mercados libres empezaron a abrirse paso, los individuos optaron por el reconocimiento de lo tuyo y lo mío, asumiendo así el principio de no agresión. A partir del proceso de descubrimiento y aprendizaje, las acciones individuales gestaron de manera espontánea los escenarios de intersubjetividad. El autor que nos ofrece un tratamiento penetrante al respeto fue Ludwig Von Mises 
(1996), quien se aproximó epistemológicamente a la propiedad como valor, y por ello resaltó su utilidad de principio para la cooperación social.

\section{Apropiación de tierras siglo XIX}

Sobre la apropiación de tierras por parte de la Iglesia, son de primera mención los títulos otorgados por la Corona española como las mercedes reales y las composiciones. Así mismo, y gracias al poder económico y político de tal institución, figuran las misiones, en ellas los indígenas eran adoctrinados en la fe católica, a la vez que en la disciplina del trabajo. La importancia de las misiones radicaba en la obtención de mano de obra, puesto que la tierra aún era abundante, no obstante, esto no desalentó la obtención de grandes extensiones terrenales, que luego eran divididas en pequeñas parcelas, unas para uso colectivo y otras para las familias indígenas, pero que sólo eran cedidas en usufructo y de manera vitalicia, pero no eran propiedad hereditaria.

Las haciendas, son también de los renglones que se cuentan dentro de las propiedades de la Iglesia regular, los jesuitas, por ejemplo, tenían grandes haciendas de ganadería extensiva, además de las dedicadas a la explotación de productos agrícolas para el comercio interno con las colonias y el comercio exterior.

Las capellanías y los censos, que en principio tenían el objeto de acumular capital, resultaron siendo un importante factor en la acumulación de tierras por parte de la Iglesia ${ }^{1}$. Los capitales y las rentas donados para la fundación de capellanías proveían el numerario necesario, por concepto de bienes muebles e inmuebles, para los posteriores préstamos a censo.

De otro lado, las capellanías actuaban como fuente generadora de crédito. Era la manera de asegurar una renta perpetua a la propia alma (dentro del marco de una ideología peculiar), de inmovilizar un capital acumulado con los trabajos de toda una vida, o de la vida de los ascendientes, en provecho y alivio del alma y de los temores que se incubaban en el lecho de muerte (Colmenares, 1983, p.89).

Los censos eran préstamos en efectivo que la Iglesia (censualista) concedía a los particulares (censatario o censuatario) pero que tenían respaldo en un bien raíz el cual quedaba hipotecado (censado). En general, la hipoteca permitió a los deudores usar la tierra para respaldar el movimiento de capitales que les habían prestado los conventos y las órdenes religiosas y los prestamistas particulares. Sin embargo, la hipoteca trajo como consecuencia el debilitamiento del dominio legal sobre las propiedades, y, por consiguiente, la modificación en la tenencia de la tierra. Pues las tierras pasaban a manos del acreedor, cuando el deudor no podía hacer frente a la deuda, originándose latifundios en poder de las comunidades religiosas. Además, en las hipotecas el inmueble sólo servía de garantía al numerario que se había entregado, es decir, lo que interesaba al acreedor eran los rendimientos y el capital, más que la explotación o la producción (Robayo, 2003). Así mismo, las cofradías, además de preocuparse por los intereses religiosos de sus asociados, manejaban el capital que recaudaban y lo mantenían en permanente circulación a título de censos entre sus clientes, descuidando la explotación de las propiedades a su cargo.

Fue para finales del siglo XVIII que se comienza a notar que es creciente el número de propiedades que no podían hacer frente a los intereses y la amortización de la deuda, así la deuda quedaba perpetuada

\footnotetext{
${ }^{1}$ Sin embargo, este no fue el objetivo con que se implementó el sistema de capellanías y de censos. El censo era una colocación de capital de recuperación muy lenta, y su redención se daba en periodos largos de tiempo, a veces de una vida completa. Pero esta lentitud se ajustaba al igualmente lento ritmo de la economía prominentemente agraria de los siglos XVII y XVIII. Los censos perpetuos no eran de los más frecuentes, y el que aparecieran así para mediados del siglo XIX, son muestra de la caducidad del sistema de crédito y del fracaso de la agricultura colonial, ante una nueva dinámica de economía liberal, basada en el comercio y la aceleración de los ritmos en los retornos de capital.
} 
y las tierras en completo abandono. La Iglesia, entonces, se apropiaba del bien y lo arrendaba para continuar sacándole alguna renta.

Para el siglo XIX, el sistema crediticio en base a censo se deteriora por la incapacidad de los deudores de salvar sus préstamos, convirtiéndose las propiedades censadas en deuda perpetua sin posibilidad de enajenación, arruinándose paulatinamente la producción agraria generada por el estancamiento progresivo de los bienes y se impide la libre circulación de éstos (Hernández y Falla, 1979, p.44).

Por otra parte, para mediados del siglo XIX, el Estado colombiano debe afrontar las exigencias de los mercados internacionales, los cuales demandan productos tropicales y materias primas. Se hace imperativa, entonces una transformación de los sectores directamente vinculados a la producción y al comercio. ${ }^{2}$ Se intenta implementar los supuestos del liberalismo económico, pero se encuentran con el latifundio eclesial, improductivo e inenajenable, que impide el establecimiento de un vivo mercado de tierras, soporte de una economía exportadora del tabaco exigido por el comercio exterior.

En los resguardos y los ejidos, como propiedad comunal, el gobierno liberal también vio un impedimento a la libre circulación de la tierra en el mercado, así como otrora, en la mano de obra esclava e indígena vio el impedimento a la libre circulación del mercado de trabajo. Sin embargo, lo que subyace en la presión a esta propiedad comunal son los intereses de los grupos de terratenientes y de comerciantes, que, ante la subida de los precios de la tierra, dado el auge agroexportador, pretenden adueñarse de los predios a la vez que abastecerse de mano de obra, pues los campesinos e indígenas, ahora despojados de sus parcelas y terrenos comunales, debían alquilar su fuerza de trabajo como peones o arrendatarios.

Otra situación que el Estado tuvo que sortear fue la falta de ingresos. Había quedado sin sus fuentes habituales, el desestanco de los monopolios comerciales y productivos, la descentralización fiscal y la reducción de impuestos y aranceles aduaneros coadyuvaron la crónica situación deficitaria. Pero no fue la única razón del déficit, pues el Estado se permitió atenderlos con recursos obtenidos de los rentistas particulares y los empresarios comerciales a través de sucesivos empréstitos con costos excesivos, aumentándose la deuda pública interna con la emisión de bonos sin respaldo en el erario público.

Es preciso resaltar que el contenido sociológico de la acción arbitraria gubernamental es un orden social en la cual institucionalmente los derechos de propiedad no cuentan con la seguridad jurídica. Así que nos enfrentamos al asunto de cómo organizar la interacción individual bajo los derechos de propiedad como núcleo central de la vida humana para contrarrestar los abusos de los grupos de poder. No se trata de un mensaje reduccionista de las libertades individuales en el sentido que hacen posible que el hombre haga vida económica sino lo contrario, para que sea posible los límites al poder, lo que importa es la participación del hombre en la vida social.

\section{Antecedentes de la desamortización}

La desamortización de bienes de manos muertas se vio como la respuesta a varios de los problemas que tenía el Estado colombiano del siglo XIX. Mientras que combatía el poder de la Iglesia, también desataba las trabas de un mercado libre y competitivo de tierras, y con este proporcionaba las condiciones al auge agroexportador. Otros objetivos a lograr, eran la consecución de recursos por ventas de los bienes expropiados que aliviarían el déficit fiscal y el pago de deudas con los particulares y la devolución de favores a la élite terrateniente. Sin embargo, los discursos al respecto pregonaban así:

\footnotetext{
${ }^{2}$ Cuyas élites se encargan de adecuar las estructuras al nuevo tipo de relaciones, permitiéndoles su consolidación como sector dominante, a través de la reforma del aparato estatal, que permite institucionalizar los cambios.
} 
La amortización eclesiástica es otro obstáculo perjudicial a la agricultura. Ya, pues, que habéis dado el primer golpe a la amortización civil, completad la obra dándolo también a la eclesiástica. Disponed que se enajenen precisamente, y sin admitir pretextos, todos los bienes raíces amortizados, pertenezcan a conventos, monasterios, capellanías, cofradías, obras pías, memorias de misas, casas de misericordia o colegios, y a las ciudades y villas; por manera que no haya uno que no vuelva al comercio de los hombres y que no pueda entrar en el domino particular, prohibiendo que esas comunidades o cuerpos puedan adquirirlos nuevamente por ningún título. Las leyes que diereis sobre esto darán vida y movimiento a una gran riqueza que está muerta para la Nación, y estimularán el interés individual fomentando el cultivo y haciendo amar la propiedad (Galindo, 1978, p.141).

Los intentos de remate de bienes que no eran utilizados a nombre de corporaciones se iniciaron casi con el mismo momento de la instauración de la República. En la década de 1820, con la extinción del tribunal de inquisición, se decretó el traspaso de todos sus bienes a manos del Estado, también el cierre de conventos menores y la apropiación por el gobierno de sus bienes y el remate de la propiedad raíz que no fuese utilizada por los colegios y beneficencias, entre otras medidas. Algunas medidas perduraron, pero en otras ocasiones la Iglesia se las arreglaba para vender ilegalmente o para hacer que les restituyeran sus propiedades.

La abolición de las manos muertas siempre fue defendida por los liberales como la forma de impulsar el libre intercambio. Sin embargo, en la década del veinte lo único que lograron fue la prohibición de toda futura conversión de propiedades en bienes de manos muertas, con lo cual adquirían el carácter de enajenables.

Con la ley del 19 de mayo de 1834, se permitió la venta de bienes de la Iglesia a censo redimible con condiciones y en 1847 se planteó la redención voluntaria de censos y de bienes de manos muertas; es decir, por motivación y consentimiento del censualista, lo cual equivalía a hacerla imposible en la mayor parte de los casos de suerte que las redenciones ejecutadas en los cuatro años anteriores habían sido insignificantes.

Con el propósito de lograr una transformación de la propiedad agraria, en la década de 1850 se incentiva la ofensiva a toda propiedad corporativa, esto incluía bienes de la Iglesia, los resguardos y los ejidos. El régimen liberal toma como medida política la inmediata abolición del régimen de excepción a que estaban sometidos los resguardos indígenas: la ley del 3 de junio de 1848 había dado a los gobiernos provinciales la facultad para arreglar todo lo relativo a resguardos de indígenas, así para su medida y repartimiento como para su adjudicación y enajenación.

En cuanto a los ejidos, estos desaparecieron en el siglo XIX por apropiación ilegal por parte de terratenientes, más que por disposición gubernamental. Ante esto, la ley del 20 de abril de 1850 sobre descentralización y organización de las rentas nacionales, permitió a las cámaras provinciales legislar para legalizar la usurpación ya dada.

\section{La Constitución y el decreto de desamortización de bienes eclesiales}

Inmediatamente después de referir los límites geográficos de la nación, así como de sus Estados, la Constitución Política de los Estados Unidos de Colombia, sancionada el 8 de mayo de 1863, entra a establecer las Bases de la Unión. Como primerísimas medidas, por un lado, prohíbe la adquisición de bienes raíces por parte de comunidades, corporaciones, asociaciones y entidades religiosas, y, por otro lado, otorga el carácter de enajenable a tal propiedad, sancionando todo contrato que tenga por objeto sacar a la propiedad inmueble de la libre circulación, tales como censos, fundaciones, legados y fideicomisos a perpetuidad. 
El artículo 15 es definitivamente iluminador, trata sobre las garantías que el gobierno general y los de los Estados, dan a sus habitantes en calidad de derechos individuales. Entre ellos están la garantía sobre la vida, la libertad individual, de imprenta, de trabajo, de expresión y de movilidad, la garantía de la igualdad, de la inviolabilidad del domicilio y del correo, la libertad de asociarse y de educarse, y el derecho de la propiedad individual. El trazo liberal de la Constitución es innegable, no sólo porque inicia con la proclamación de tales garantías individuales, sino por el tratamiento que les da a puntos como la libertad individual: que no tiene más límites que la libertad de otro individuo: es decir, la facultad de hacer u omitir todo aquello de cuya ejecución u omisión no resulte daño a otro individuo o a la comunidad. Parte de un supuesto nominalista, y puede decirse preliminarmente que apunta hacia las relaciones entre personas.

Cabe resaltar que tales garantías individuales no fueron fundadas en la constitución de Rionegro. Sus antecedentes legales ya se encuentran en la Constitución Política de la Confederación Granadina, de 1858 y en la Constitución Política de la Nueva Granada, de 1853.

En esta última, en el artículo 5, La República garantiza a todos los granadinos la libertad individual, la inviolabilidad de la propiedad, la libertad de industria, la igualdad y todas las demás garantías, que posteriormente son recogidas en los últimos capítulos de la Constitución de 1858, más precisamente en el capítulo quinto, artículo 56, como Derechos Individuales.

Es relevante a nuestro asunto, resaltar que las tres constituciones tienen concomitancia en la restricción al derecho individual de la propiedad, la cual determina que el individuo gozará de tal derecho, excepto:

Por pena o contribución general, con arreglo a las leyes, o cuando así lo exija algún grave motivo de necesidad pública, judicialmente declarado y previa indemnización. En caso de guerra la indemnización puede no ser previa, y la necesidad de la expropiación puede ser declarada por autoridades que no sean del orden judicial (Constitución Política de los Estados Unidos de Colombia, 1863, p. 8).

Volviendo a la enajenabilidad de la propiedad, establecida en las Bases de la Unión de la Constitución de 1863 , también se refiere que tal asunto ya se había tratado y reglamentado en el Decreto del 9 de septiembre de 1861 y en los decretos que de él derivaron sobre procedimientos y establecimiento de las instituciones necesarias al mantenimiento de una libre circulación de la propiedad raíz en el mercado.

El decreto de 9 de septiembre de 1861, trata sobre la desamortización de bienes de manos muertas. Se dio cuando ejercía la presidencia de los Estados Unidos de Nueva Granada el General Tomás Cipriano de Mosquera, y partió de las siguientes consideraciones:

Que es la circulación de la propiedad raíz, la base de la riqueza pública; que ya desde la constitución de 1858 , sólo se reconoce propiedad a los individuos, y no a corporaciones, congregaciones y sociedades anónimas, las cuales no pueden poseer bienes inmuebles a perpetuidad; que los bienes de manos muertas han producido complicaciones en las economías de los países y que la nación sucede en la posesión los bienes de las corporaciones que dejan de existir, entre otros.

Tal decreto hizo que las propiedades y los derechos, acciones y capitales de censos, de las corporaciones civiles o eclesiales y establecimientos de educación y de beneficencia pasaran a manos de la Nación; prohibió los censos sobre propiedades a favor de corporaciones, y a perpetuidad.

Pero en concordancia con las libertades individuales y el carácter liberal de la época, ordena que las fincas, ya en manos del Estado, sean enajenadas en subasta pública, y antes divididas en porciones tan pequeñas como sea posible, para aumentar la competencia. En este mismo sentido, ofrece la garantía individual diciendo que las disposiciones aquí consignadas no incluyen a los censos o capitales puestos a 
interés de propiedad individual y que no tengan el carácter de fundación a favor de los establecimientos de que trata este decreto.

En cuanto a las tierras baldías la Constitución de 1863 establece que: Las tierras baldías de la Nación, hipotecadas para el pago de la deuda pública, no podrán aplicarse sino a este objeto, o cederse a nuevos pobladores, o darse como compensación y auxilio a las empresas para la apertura de nuevas vías de comunicación.

Y en cuanto a las tierras de los indios se expresa así en el Capítulo XI sobre Disposiciones varias:

Art. 78. Serán regidos por una ley especial los Territorios poco poblados, u ocupados por tribus de indígenas, que el Estado o los Estados a que pertenezcan consientan en ceder al Gobierno general con el objeto de fomentar colonizaciones y realizar mejoras materiales (Constitución Política de los Estados Unidos de Colombia, 1863, p. 33).

\section{Algunos rasgos de liberalismo}

Entre los ilustres pensadores de la época era clara la preocupación por la implementación de las ideas liberales en una economía enquistada aún en las tradiciones del antiguo régimen. No fueron pocas sus disertaciones alrededor de nociones que ideológica y teóricamente sustentaban la implementación de un mercado libre. Así, pueden encontrarse discusiones sobre la función de los bancos, la inserción del papel moneda, el trabajo, la propiedad, la libertad, la intervención del Estado, entre otros.

La desamortización de bienes de manos muertas, por ejemplo, si bien parecía algo más que necesario para la creación de un mercado libre de tierras, dio pie a la publicación de varios comentarios, artículos y pequeños tratados justificatorios. Pues las medidas tomadas en el asunto representaban una contradicción a las ideas liberales que se querían defender:

Que el decreto que los expropia arrebata esperanzas de posesión de muy antigua fecha, e introduce un principio de desconfianza y de alarma contrario al espíritu del derecho de propiedad; porque propiedad es esperanza, es confianza, es seguridad en el goce pacífico de los bienes terrenales. Confesémoslo francamente e investiguémoslo si hay consideraciones de más alto interés que puedan justificar esta violación aparente de un principio sagrado (Camacho, 1983, p.146).

También Galindo (1978) agudo estudioso de la economía colombiana, planteó la misma inquietud en cuanto a la adjudicación de baldíos, pero de manera más perspicaz, por cuanto ponía en entredicho la intervención del Estado, y la forma del mercado del siglo XIX:

Nación, ¿deberes de otro orden que llenar, distintos de los de simple comerciante en tierras baldías? O mejor dicho ¿puede o debe el Gobierno desprenderse de la propiedad de dominio público sobre las tierras baldía, para constituir la de dominio privado, sin consideración al objeto económico de esta enajenación, a los derechos naturales del hombre a la accesión del desierto, ni a las necesidades ni a la independencia política y personal de las generaciones presentes y futuras? (p. 189-198).

Camacho (1983) partía de la propiedad territorial como construcción no deliberada de la acción humana: principio propio de la sociedad civil, institución nacida en el seno de la civilización, establecida y asegurada en virtud de la conveniencia general, y sujeta al examen y a la revisión que la misma conveniencia universal pueda exigir, en este sentido, se adscribía a las nociones liberales de la propiedad. Pues era una propiedad que no estaba garantizada por la voluntad divina, sino por la conveniencia general, haciendo referencia a que la propiedad territorial había cambiado según los grados de adelanto 
de la civilización humana. Así, la primera forma de propiedad había sido pasajera, acorde con las tribus nómadas; luego el desarrollo de la agricultura vinculó la propiedad a las familias, en los mismos términos en que para el XIX existía en los resguardos indígenas; en el régimen feudal la propiedad recaía sobre los jefes militares encargados del gobierno; la fase que le siguió fue la de la posesión a través de títulos nobiliarios; y finalmente la forma más acabada y perfecta de la apropiación del suelo: la propiedad individual, enajenable, divisible sin restricciones y transmisible a los hijos.

Pero nuevamente, es Galindo (1978) quien de hace una mayor precisión y explicación del origen de la propiedad y de su importancia:

El derecho de propiedad es la urdimbre misma sobre la cual reposa el orden social. La historia nos enseña que muchos pueblos han podido levantarse a las más altas cimas de la grandeza humana, sin el goce de las libertades políticas, sin libertad de conciencia, sin libertad de imprenta, sin libertad de asociación; pero donde el hombre no puede contar con algo seguro para la vida, el territorio se convierte en un yermo y la sociedad en hordas de tribus errantes. Mientras la naturaleza humana sea ésta (...); mientras las necesidades que causen este dolor no puedan satisfacerse sino por la riqueza; y mientras no hay otro medio de producir la riqueza que el trabajo, la propiedad será la primera condición de todo progreso y de toda civilización (p. 204).

Según Ghersi (2008) la consideración de la propiedad como derecho individual, se sustenta en el nominalismo y en el derecho subjetivo, respectivamente. El primero, deshace los universales a través de los cuales se explicaba el movimiento de la naturaleza y de las civilizaciones mismas, para centrar los análisis en el individuo, y en consonancia, el segundo, propone al hombre como sujeto de derecho.

Si bien, Camacho no explicitó el derecho subjetivo que enmarcaba los derechos de propiedad, la simple reivindicación de garantías individuales, dejan entrever que este autor, comprendía en la propiedad no sólo el telón de fondo sobre el cual se desenvolvía la sociedad civilizada, sino también la condición por la cual un individuo se constituyera como tal.

Por su parte, las constituciones de 1853,1858 y 1863 son tributarias del derecho subjetivo. Primero porque tratan de las garantías para los individuos dentro de su articulado, el cual incluye a la propiedad privada; y segundo, porque la Constitución de Rionegro, en materia específica de la propiedad sobre la tierra, no admite una propiedad corporada, la cual no es consecuente con la concepción de propiedad privada liberal y subjetiva.

Sin embargo, el subjetivismo (el individuo como centro) de las constituciones, y tendríamos que decir, que el de Camacho también por haberlas defendido, no son completos. Las constituciones guardan restricciones no sólo a la propiedad, sino también a la misma ciudadanía (Constitución de los Estados Unidos de Colombia, 1863, p.15). Como se mencionó, la propiedad sería afectada en caso de grave motivo de necesidad pública o en caso de guerra, dos inconvenientes que no fueron fortuitos, sino permanentes durante el siglo XIX, sin contar con que la Constitución de 1858 además privaba al individuo de su propiedad vía pena o contribución general.

En cuanto a la categoría de ciudadano, las limitaciones son más sutiles. Por un lado, aunque contemplan que son colombianos todas las personas que nazcan en territorio de los Estados Unidos de Colombia, entre otras bondades, en la Constitución de 1858 sólo pueden elegir y ser elegidos para los puestos públicos los varones mayores de 21 años que sean casados o lo hayan sido (Constitución Política para la Confederación Granadina, 1858, p.5-6); la Constitución de 1863, suaviza la restricción y comenta 
que la condición sólo se aplica a quienes van a ser elegidos a los puestos públicos del gobierno general (Constitución Política de los Estados Unidos de Colombia, 1863, p.16). ${ }^{3}$

Es decir, que en primera instancia ya están excluidos las mujeres y los que decidan no hacer demostración de su adhesión a la fe católica a través del matrimonio. Pero hay otro grupo de individuos excluidos de forma implícita de la ciudadanía por no ser civilizados:

Art. 78. Serán regidos por una ley especial los Territorios poco poblados, u ocupados por tribus de indígenas, que el Estado o los Estados a que pertenezcan consientan en ceder al Gobierno general con el objeto de fomentar colonizaciones y realizar mejoras materiales.

Desde que un territorio cuente población civilizada que pase de tres mil habitantes, mandará a la Cámara de Representantes un Comisario, que tendrá voz y voto en la discusión de las leyes concernientes a los Territorios, (...) (Constitución Política de los Estados Unidos de Colombia, 1863, p.33).

El artículo se encuentra en el Capítulo XI, Disposiciones Varias, y a partir de él pueden hacerse las siguientes inferencias: los territorios indígenas, se consideran, en primer lugar, como territorios poco poblados; en segundo lugar, como territorios que pertenecen no a los indígenas sino al Estado, por lo cual éste puede disponer de ellos para fomentar colonizaciones; y tercero, dado que los indígenas no son civilizados, entonces pueden quitárseles las tierras, pues como no son ciudadanos no gozan de las garantías individuales: derecho a la propiedad. El segundo párrafo del artículo hace el contraste entre indígena y civilizado, lo que da pie para afirmar que, mientras del primero el Estado puede disponer de sus territorios, el segundo tiene derecho a la participación política sobre las decisiones que se tomen sobre los territorios.

Los intereses del individuo que se intentan consignar en las Constituciones como derechos o garantías individuales, son superados por los intereses nacionales. En este sentido, el subjetivismo del derecho es remplazado por otro universal, el Estado. El punto inicial para la recurrente arrogancia gubernamental es la ausencia de mecanismos de control por parte de los individuos.

Si bien es cierto que el libre mercado gira alrededor de los bienes materiales, los incentivos de carácter económico no son los únicos. Varios pensadores han constatado que el hombre no pierde de vista la cooperación social desde el mundo del trabajo, ello significa, que emerge el reconocimiento social. Así que los derechos de propiedad tienen que leerse a este nivel. No se trata de vivir en un mundo humano aséptico de arbitrariedades y la coacción fáctica sino de la apertura a la conciencia individual que da paso a la imposición de los límites.

La persistencia que el mundo humano puede ser diseñado desde la razón es una idea que persiste en el orden social, por supuesto, que este escenario fortalece el argumento que la acción individual no es la base del Estado. Frente a esta posición que hace sombrío el horizonte epistemológico de los derechos de propiedad, es imperioso abrir una discusión filosófica para tratar de examinar las consecuencias esperadas del racionalismo constructivista. La sustitución de las relaciones espontáneas por las deliberadas es una declaración científica perjudicial pues se asiste a un progresivo desmantelamiento de los saberes propios de la experiencia humana. Es por ello, que los filósofos liberales en su reflexión de la razón llaman la atención sobre los daños a los individuos que esto puede causar, vale decir, las directrices de política estatal propician la destrucción del conocimiento del hombre y al nacimiento de la barbarie. Por eso el acercamiento del liberalismo en su análisis de las relaciones espontáneas es bienvenido.

\footnotetext{
${ }^{3}$ También es de anotar que en la Constitución de la Confederación granadina era posible perder la ciudadanía por causa criminal o enajenación mental, parágrafo que desaparece en la Constitución de Rionegro.
} 
De regreso a las consideraciones de Camacho, continuamos con las consecuencias que él vio a la reforma a la tenencia de la tierra, el Decreto de desamortización de bienes de manos muertas. Después de que el político liberal estableciera la importancia de la propiedad en una sociedad y su carácter sagrado en términos laicos, intenta justificar la existencia y la implementación de un decreto que expropiaba.

Para ello, hace un extenso listado de los beneficios que se extraerían que son ante todo económicos y sociales, menciona puntos como: la división de las grandes propiedades, la cual fortalece la circulación de la propiedad, la sustitución de los cultivos en arrendamiento por cultivos del mismo propietario y la difusión de la propiedad entre mayor número de propietarios; el fomento de la competencia entre agricultores; el empleo de capitales, ya no en deuda flotante y usura, sino en finca raíz y en la empresa de la agricultura, y con esto el descenso en los intereses de los capitales; la desaparición de los censos perpetuos; y finaliza con que los ingresos que el Estado pueda generarse redundarán en beneficios para todos.

También argumenta que la desamortización de bienes de manos muertas para nada es una confiscación a los censualistas, y en este sentido respeta y garantiza la propiedad. Pues el decreto de 1861 paga y reconoce los intereses de tales fundaciones y el decreto de Crédito Nacional, también del 9 de septiembre de 1861, manifiesta:

Art. 6. Se reconocerán igualmente en inscripciones del 6 por 100 de interés anual, asimilada a la deuda consolidada de Rentas sobre el Tesoro la procedente de censos perpetuos al redimir i quitar, los que se hayan redimido, o que desde la publicación del presente decreto redima los particulares para libertar sus fincas (Presidencia de la República, 1861, p.10).

Camacho además cita una circular del 25 de octubre de 1861, provenientes de la Secretaría de Hacienda por orden del Poder Ejecutivo:

Los censos así redimidos se reconocerán sobre el Tesoro y se emitirá en cambio vales de renta al 6 por 100, en proporciones equivalentes, a fin de que la renta que deba pagar el Tesoro, a virtud de la redención, corresponda exactamente en su cuantía a la renta que deje de deber por los vales de deuda interior consignados (Camacho, 1983, p.161).

De manera que la operación de que se trata no implica, respecto de la deuda interior, alteración de ninguna especie, ni a favor ni en contra del Tesoro, ni a favor ni en contra del censualista, ni a favor ni en contra del censuatario, en cuanto a las respectivas rentas; es simplemente una traslación de éstas, para suprimir las dificultades que oponen los censos a la circulación y al progreso de la riqueza raíz (Camacho, 1983, p.162).

Tenía razón Camacho cuando escribió que los censos son el cáncer de la propiedad raíz, puesto que le han quitado su carácter de individual. A parte de lo ya tratado sobre el derecho subjetivo, derivamos otra implicancia. El que la propiedad ya no sea individual significa también que no es una relación entre personas. Dicho de otro modo, se debaten los derechos de propiedad entre ser: personales - relación entre personas - o reales - relación entre las personas y las cosas - puesto que a la propiedad del siglo XIX el censo le representa una lapa.

La propiedad transmisible a los hijos, es una ilustración de los derechos de propiedad personales, por cuanto se reconoce de persona a persona el derecho, y la sociedad en su conjunto también los reconoce. Pero para que la figura de la hipoteca sea exitosa, ha sido necesario que el gravamen recaiga sobre el bien, y esto viene así desde el mismo derecho romano que aún hoy nos cobija.

Los censos, como se ha visto funcionan como hipotecas a perpetuidad, aunque no todos fueron así, donde el bien censado cargaba con la deuda, y para que ello fuera posible era necesario considerar que 
era el bien hipotecado o censado el que guardaba el atributo de la propiedad. Así, aunque una persona quiera transar con otra un bien raíz, en el marco del derecho personalista, la seguridad de la propiedad se pierde en un contexto de censos de bienes de manos muertas por doquier, porque tal bien raíz puede contener un gravamen oculto. El ejemplo extremo está en la situación en que el censo del siglo XIX pone a la propiedad territorial, haciéndola indivisible, pues el gravamen pesa con igual fuerza sobre el todo y sobre cada una de sus partes, situación que sólo es posible, cuando la cosa tiene el atributo de la propiedad por sí misma:

Un censo de \$3.000 sobre una finca de tres hectáreas de extensión, si ésta se divide en lotes de a una hectárea entre tres propietarios, grava cada lote no con la acción de \$1.000, sino con la de \$ 3.000 , y la totalidad de los réditos vencidos podría cobrarse indistintamente de cada uno de los tres propietarios en que se ha dividido la finca (Camacho, 1983, p.158).

Por su parte, la reglamentación de la desamortización de bienes de manos muertas, actúa en consonancia al derecho real de la propiedad. En varias ocasiones manifiesta, incluso Camacho también lo reitera cada vez que puede, que se hace necesaria la intervención normativa para darle vía libre a la circulación de la propiedad, es decir, que los derechos de propiedad puedan pasar de mano en mano sin restricciones. Y puede que sea posible una reactivación de la circulación en un mercado de derechos, pero lo cierto es que, para la conformación de un mercado moderno, de tierras o cualquiera otro bien, esta no es condición suficiente (Chaufen, 2009). ${ }^{4}$

La gran concentración de la propiedad siguió vigente, ahora en manos terratenientes laicas, la implementación de la ley desde arriba no causó los efectos esperados, es decir, en cuanto a desarrollo del mercado. La propiedad territorial se sigue fundando sobre el monopolio, ahora ya no del derecho de conquista, sino de la ley en su carácter deliberada; si la propiedad se hubiera fundado sobre el principio científico de que el único fundamento legítimo del valor de la tierra es la apreciación subjetiva del trabajo humano incorporado en ella, su distribución muy seguramente habría sido otra, tal vez más igualitaria ante la ley y más competitiva, tanto en términos políticos como económicos.

Tanto la redención de los censos como la supresión de los diezmos beneficiaron mayormente al latifundio neogranadino, igualmente favorecido con la liberación de la fuerza de trabajo esclava y con la extinción definitiva de la mayoría de los resguardos indígenas. Razón por la cual se ha considerado que las reformas liberales de mediados del siglo XIX en lo que respecta al sector agrario fueron tímidas, combatieron el latifundio eclesiástico, pero retrocedieron ante el latifundio laico, y éste no sólo aumento en extensión, sino que legalmente se consolidó (Díaz, 1977).

Es preciso ir más allá de las posturas caracterizas por la unilateralidad, al considerar que el mundo humano es una sucesión de encuentros individuales. Se olvida que la concurrencia de las acciones humanas es un a priori político y social, por tal motivo no se puede pretender que, desde la razón calculadora, la sociedad se construye desde la nada. Insistir en la línea constructivista desemboca en la negación del individuo como unidad política y no de menor importancia, a la apertura de propuesta totalizantes, como también a la emergencia del intérprete de la acción humana.

En la medida que los hombres aceptemos que las relaciones espontáneas puedan ser sustituidas por relaciones intencionadas, la posibilidad de conocer el mundo de nuestra experiencia se diluye. Lo cierto es que dicha actitud ante nuestra vida hace excusable la arbitrariedad en el sentido que reconocemos el bien común está por encima del bien individual. El peligro que se vislumbra y que filósofos liberales llaman la atención es que la lucha política pierde de vista la defensa de los derechos de propiedad privada.

\footnotetext{
${ }^{4}$ La forma de usar la propiedad esencial para la economía es la transferencia de dominio. Los intercambios son, por su naturaleza, una transferencia de dominio. Domingo de Soto reconoció que "no existe nada más conforme a la justicia natural que respetar la voluntad de una persona que desea transferir el dominio de sus bienes" (p.85).
} 


\section{Consideración final}

¿Qué queda de todo esto? Hay un propósito políticamente correcto, los acontecimientos no pueden dejarse a la aleatoriedad. Ellos son la consecuencia de una política con un marcado acento en el empleo de los resortes institucionales para la represión de las libertades individuales. El argumento de esto consiste en brindar condiciones que garanticen complacencia por parte de los individuos mediante incentivos, pero además señalar una cierta tendencia a la constitución de órdenes sociales perfectos, con lo cual se crea un escenario de hipernormalización que hace perder de vista el objetivo de la realidad humana. La preferencia por la mente calculadora en el ámbito humanístico con el objeto de redefinir la vida humana, da lugar a que indaguemos sobre la intención de dejar por fuera los aspectos intelectuales y morales de nuestras relaciones. Mientras estos aspectos se mantengan por fuera se hace imposible ampliar el horizonte de comprensión del principio de no agresión. Este es el lugar para averiguar la importancia de la libertad entendida como el derecho a la vida y a la propiedad. Desde esta consideración, resulta importante señalar que la experiencia humana es un tránsito de fallos y aciertos.

Pero en el momento en que los individuos acometen la comprensión de su experiencia se extravían en el laberinto de la ignorancia inducida, de tal manera que la seguridad del bien común abre paso al terror como mecanismo de poder:

Hoy en día vivimos en un escenario que toma distancia de los principios liberales, y esto podría ser consecuencia de que los individuos, en su infinita ilusión conformista, hayan sustituido el ejercicio libre de la acción por las reglas gubernamentales. Ahora bien, cómo se explica esto. Dado que el individuo con anterioridad ha sido vaciado de sus experiencias y costumbres para vivir con otros, entonces se hace necesario la presencia de un planificador que ordene. No comprender que esto ha sido la decepción de la vida social, es una de las principales dificultades para llevar a cabo el proceso civilista (Salazar, 2018, p. 66).

De ahí resulta que en el horizonte histórico y cultural la libertad individual brilla por su ausencia. Lo básico es proponer que a los hombres les conviene rescatar la certeza moral sobre la inviolabilidad de sus derechos personales porque ello ayuda a la convivencia civilista.

\section{Referencias}

Camacho, S. (1983). Desamortización de bienes de manos muertas. Bogotá, Colombia: Editorial Incunables. Colmenares, G. (1983) El crédito en una Economía Agrícola. En Sociedad y economía en el Valle del Cauca Tomo 1 Cali: Terratenientes, mineros y comerciantes siglo XVIII. (pp. 79-94). Bogotá, Colombia: Universidad del Valle - Fondo de Promoción de la Cultura del Banco Popular.

Chafuen, A. (2009). Raíces cristianas de la economía libre de mercado. Madrid, España: El Buey Mudo.

Congreso de la República de Colombia (1853). Constitución Política de la Nueva Granada. Bogotá D.C.: Congreso de la República de Colombia.

Convención Nacional (1863). Constitución Política de los Estados Unidos de Colombia. Bogotá, Colombia: Imprenta y estereotipia de Medardo Rivas.

Senado y Cámara de Representantes de la Nueva Granada (1958). Constitución Política para la Confederación Granadina. Bogotá D.C.: Senado y Cámara de Representantes de la Nueva Granada. Recuperado de https://www.funcionpublica.gov.co/eva/gestornormativo/norma.php?i=13697

Díaz, F. (1977). La desamortización de bienes eclesiásticos en Boyacá. Tunja, Colombia: Ediciones la Rana y el Águila.

Galindo, A. (1978). Estudios Económicos y Fiscales. Bogotá, Colombia: Biblioteca popular de economía Anif - Colcultura. Recuperado de https://www.sogeocol.edu.co/documentos/est_econ_y_fisc.pdf

Ghersi, E. (2008). Conceptos de derechos de propiedad. Conferencia llevada a cabo en la Universidad Francisco Marroquín, Guatemala, Guatemala. Recuperado 
de http://articulos.ghersi.com/2011/08/capitulo-9-\%e2\%80\%93-dos-conceptos-de-derecho-depropiedad/

Hernández, M. y Falla, P. (1979). La desamortización de bienes de manos muertas (Tesis de pregrado). Universidad Nacional de Colombia, Bogotá, Colombia.

Mises, L. (1996). Sobre Liberalismo y Capitalismo. Barcelona, España: Ediciones Folio.

O’Driscoll Jr. G. P. y Hoskins. L. (2006). Derechos de propiedad: La clave del desarrollo económico. Cato Institute. 1-12. Recuperado de http://www.hacer.org/pdf/pr.pdf

Presidencia de la República de Colombia (1861). Decreto de 9 de setiembre de 1861, en RECOPILACION de las disposiciones fundamentales y reglamentarias sobre Crédito nacional y desamortización de bienes de manos muertas. Bogotá, DC.: Presidencia de la República de Colombia. Recuperado de http://www.banrepcultural.org/sites/default/files/brblaa877214.pdf

Robayo, J. M. (2003). La propiedad rural en Boyacá: de las reformas de mitad del siglo a la Constitución de Rionegro. Tunja, Colombia: Universidad Pedagógica y Tecnológica de Colombia.

Salazar, F. (2018). El orden social en Colombia: una interpretación. Revista de Economía del Caribe, (22), 4768. doi: 10.14482/ecoca.22.337

Salazar, F. (2011). Colombia: Teoría e historia. Medellín: Samava Impresiones.

Salazar, F. y Cuaspud, A. L. (2013). Mercantilismo Español y Derecho Indiano. Títulos sobre tierras en la Gobernación de Popayán. Revista Ensayos de Economía, 23(43), 161-179. Recuperado de https://revistas.unal.edu.co/index.php/ede/article/view/42933

Smith, A. (1996). Lecciones de Jurisprudencia, Madrid. España: Centro de Estudios Políticos y Constitucionales. 